\title{
artículos
}

\section{Sedimento material de una vida humanista. El inventario de bienes de Pablo de Céspedes}

\author{
Pedro M. Martínez Lara \\ Universidad de Sevilla
}

\section{RESUMEN}

El 26 de julio de 1608 fallecía en Córdoba Pablo de Céspedes. Al día siguiente, albaceas y escribanos comenzaron el proceso de inventario de sus bienes. En 1903, Ramírez de Arellano publicó por primera vez el documento que ahora ha sido transcrito de nuevo. El análisis del mismo, que quedó entonces pendiente, y su cotejo con lo que la historiografía moderna y otras fuentes documentales han proporcionado sobre el racionero, han permitido formular algunas hipótesis, arrojando nuevas luces sobre la figura del humanista y pintor.

PALABRAS CLAVE: Pablo de Céspedes/ Inventario/ Coleccionismo/ Humanismo/ Renacimiento.

Material sediment of an humanist life. Pablo de Céspedes' inventory of properties

\section{ABSTRACT}

On July 26th, 1608, died in Cordoba Pablo de Céspedes. The next day, executors and scribes began the inventory of his properties and reflected it in an affidavit. In 1903, Ramirez de Arellano first published the named document that now has been transcribed again. Its analysis, which remained then pending to be done, and its comparison for verification with what has been supplied about Pablo de Céspedes by the modern historiography and other sources, have allowed to formulate new hypothesis and have shed light on the figure of this humanist and painter. Renaissance.

KEY WORDS: Pablo de Céspedes/ Inventory/ Collecting/ Humanism/

Con la publicación en 1903 del estudio sobre Pablo de Céspedes ${ }^{1}$, Rafael Ramírez de Arellano y Díaz de Morales marcó un punto de inflexión en la historiografía sobre el racionero cordobés ${ }^{2}$. Este cambio vino dado, de una parte, por el nuevo tratamiento que se le daba a la información, y de otra, por el análisis documental que aparecía por primera vez en un estudio sobre Céspedes. Entre los manuscritos que

* MARTíNEZ LARA, Pedro M.: "Sedimento material de una vida humanista. El inventario de bienes de Pablo de Céspedes", en Boletín de Arte $n^{\circ}$ 32-33, Departamento de Historia del Arte, Universidad de Málaga, 2011-2012, págs. 437-455. Fecha de recepción: Diciembre de 2011.

1 Los trabajos más actualizados sobre este insigne personaje son: RUBIO LAPAZ, Jesús: Pablo de Céspedes y su círculo. Humanismo y contrarreforma en la cultura andaluza del Renacimiento al Barroco. Granada, Universidad de Granada, 1993; RUBIO LAPAZ, Jesús y MORENO CUADRO, Fernando: Escritos de Pablo de Céspedes. Edición crítica. Córdoba, Diputación Provincial, 1998; DÍAZ CAYEROS, Patricia: "Pablo de Céspedes entre Italia y España" Anales del Instituto de Investigaciones Estéticas, nº.75, México D.F., 2000, pp. 5 - 60; y REDÍN MICHAUS, Gonzalo: Pedro Rubiales, Gaspar Becerra y los pintores españoles en Roma, 1527 - 1600. Madrid, CSIC, 2007, pp. 266 - 271.

2 El estudio se encuentra en: RAMÍREZ de ARELLANO y DÍAZ de MORALES, Rafael: "Artistas Exhumados. Pablo de Céspedes pintor, escultor, arquitecto, literato insigne y músico", Boletín de la Sociedad Española de Excursiones, n.11, Madrid, 1903, pp. $204-214$ y 232 - 236; n. 12, Madrid, 1904, pp. $34-41$. 
Arellano extrajo de la sección de protocolos notariales del Archivo Histórico Provincial de Córdoba para su publicación, estaba el inventario post-mortem del racionero Céspedes. Pese a aparecer editado hasta en dos ocasiones, su contenido no tuvo tanta relevancia como el hecho en sí de su hallazgo y divulgación ${ }^{3}$. Aunque digno de elogio -después de todo suya es la primicia-, el análisis y posteriores conclusiones de este autor no fueron rigurosos. El erudito se atuvo a los supuestos de la escuela historiográfica vigente, lo que restó rigor científico a lo escrito.

Humanismo y colección en Italia y Andalucía. En torno a Pablo de Céspedes.

Durante el Renacimiento, los grandes humanistas, especialmente los cortesanos, reunieron en sus gabinetes importantes colecciones de objetos. Continente y contenidos que, aparte de la mera función estética de generar un ambiente o escenografía del prestigio en el interior de sus moradas, servían como soporte para la reflexión, erudición, estudio y tertulia. Esta actividad tuvo su origen en las cámaras maravillosas de la Edad Media. Transformada sustancialmente durante el Renacimiento por la mentalidad humanista, para dar lugar a lo que algunos especialistas han considerado la forma embrionaria del museo actual ${ }^{4}$.

El coleccionismo como práctica humanista estuvo también presente en el territorio andaluz. En la comunidad de aristócratas y eruditos andaluces, entre los que cabe destacar a los moradores de la Casa de Pilatos, Gonzalo Argote de Molina, o el cardenal Rodrigo de Castro, hubo importantes recopilaciones que seguían el modelo italiano. No obstante, las fuentes no hablan de coleccionismo, sino de "anticuarios"5. Parece claro que el modelo a seguir por estos, está en Paolo Giovio, un personaje que además de constituir un excelente ejemplo de uomo virtuoso, reflejó su actividad humanística en los Elogia veris clarorum virorum6. Pieza en la que, entre otras cosas, se dedica al contenido de su llamado "museo", instalado en su casa de Como.

3 El documento original se encuentra en el Archivo Histórico Provincial de Córdoba (en adelante A.H.P.Co.) Secc. Protocolos Notariales, Leg. 12.441P, 1608, s/f.; apareció transcrito en el trabajo que se acaba de citar apareciendo igualmente transcrito, años más tarde, en: RAMÍREZ de ARELLANO y DÍAZ de MORALES, Rafael: Ensayo de un catálogo biográfico de escritores de la provincia y diócesis de Córdoba con descripción de sus obras. Madrid, Revista de Archivos, Bibliotecas y Museos, 1921 - 1922, pp. 130 - 150. Más recientemente se ha vuelto a referenciar la existencia de este original. Vid. TORRE y del CERRO, José de la: Registro documental de pintores cordobeses. Córdoba, Diputación Provincial, 1988, p. 247.

4 Aunque fue publicado hace más de un siglo, el estudio de Schlosser sigue plenamente vigente. Vid. SCHLOSSER, Julius von: Las cámaras artísticas y maravillosas del Renacimiento tardío. Torrejón de Ardoz, Akal, 1988.

5 La terminología adquiere aquí una importancia capital, pues hace confluir la emulación del ideal italiano y el referente clásico, esto es, la veneración por la Antigüedad. Recientemente el profesor Urquizar ha publicado un estudio donde se aborda esta transposición del modelo italiano al medio andaluz. Vid. URQUIZAR HERRERA, Antonio: Coleccionismo y Nobleza: Signos de distinción social en la Andalucía del Renacimiento. Madrid, Marcial Pons, 2007. Especialmente el capítulo dedicado a los señores y el modelo humanístico, p. 54 y ss.

6 El título completo de la obra es Elogia veris clarorum virorum imaginibus apposita quae in musaeo louiano comi spectantur y fue editado en Venecia en 1545 por Michele Tramezzino. La pieza literaria resultó todo un hito en su momento y se difundió rápidamente, primero por su entorno inmediato, mediante copias manuscritas que corrían literalmente de mano en mano, y, poco después, impreso por todo el continente. 
Aparte de lo que proporcionan los documentos notariales, lo que se sabe sobre el medio andaluz viene dado por obras similares a los Elogia. El Libro de verdaderos retratos de Pacheco es el que más información proporciona ${ }^{7}$, sin dejar de lado otros textos como Varones Insignes de Rodrigo Caro, donde se da cuenta de la actividad humanística y anticuaria de Arias Montano en su peña de Aracena. Incluso, el propio Rodrigo Caro tenía un lugar de retiro y una colección en su Utrera natal ${ }^{8}$. Pablo de Céspedes no fue aristócrata ni hombre poderoso, fue pintor pero tampoco vivió de lo que pintaba. Se había garantizado el sustento y el estatus social mediante el acceso al cabildo de la Catedral de Córdoba, de la que fue racionero entero desde 1577 hasta su muerte. Esto le permitió vivir holgadamente y la posibilidad de practicar la pintura, la literatura, la poesía y otras artes con gran dedicación. También mantuvo contacto con los personajes más relevantes de su tiempo, participando en las tertulias y academias sevillanas. Cuestión, esta última, que le posibilitó la transmisión al entorno andaluz de los presupuestos que había aprendido en Italia en círculos igualmente de enorme relevancia, como el del cardenal Alessandro Farnese, o en la mismísima Accademia dei Virtuosi al Pantheon. No obstante su cargo eclesiástico, sus emolumentos no le proporcionaron una fortuna que le posibilitase la adquisición de una gran colección ni la formación de un museo. Por esa razón, el contenido de este inventario de bienes debe ser considerado en la medida de las posibilidades y posición de su dueño. Para ello, tras el análisis, se abordará su comparación con el de un coetáneo que se movió en un ambiente similar, Luciano Negrón ${ }^{9}$, cuyo estudio fue publicado por el profesor Luis Méndez. Canónigo de la Catedral de Sevilla, visitador de iglesias del Arzobispado, consultor del Santo Oficio y mayordomo de la fábrica de la Catedral de Sevilla, desempeñó papeles clave para la institución capitular. Fue también un humanista reconocido e integrado en las academias sevillanas. Junto con el canónigo Pacheco, sería responsable de las empresas artísticas más importantes del cabildo hispalense durante el último tercio del Quinientos, actuando ambos como ideólogos y, en el caso de Negrón, contratando a los artistas que las hicieron posible. De este modo, nacieron programas decorativos e iconográficos como los de la custodia de

7 Vid. PACHECO, Francisco: Libro de descripción de verdaderos Retratos, de llustres y Memorables varones. Madrid, s/f. Manuscrito original reproducido en foto-cromo-typia por la Librería Española y Extranjera de D. Rafael Tarasco, s.a. (Edición digital de la B.U.S.). En esta obra aparecen referencias a la actividad anticuaria de algunos de estos humanistas, como Gonzalo Argote, que había reunido en su casa de Sevilla un curioso "museo", o bien la colección de "antigüedades" que Francisco de Medina, quien por cierto había estado en Italia, formó en su hacienda, pp. 131 y ss., y 155 y ss. Vid. BASSEGODA i HUGAS, Bonaventura: "Cuestiones de iconografía en el libro de retratos de Francisco Pacheco", Cuadernos de Arte e iconografía, n. 7, Madrid, 1991, pp. 186 - 196, y del ya citado trabajo de Urquizar: URQUIZAR HERRERA, Antonio: Coleccionismo y Nobleza... op. cit., p. 58 y 59 .

8 Vid. URQUIZAR HERRERA, Antonio: Coleccionismo y nobleza...op. cit., p. 58, según se desprende de CARO, Rodrigo: Varones insignes en letras naturales de la ilustrísima ciudad de Sevilla: epistolario, precedidos de un estudio biográfico-crítico de Santiago Montoto. Sevilla, Real Academia Sevillana de Buenas Letras, 1915. Se trata de la primera edición de estos textos, inéditos hasta entonces. Sobre el humanista utrerano vid. CAMPO, Agustín del: "Ocios literarios y vida retirada en Rodrigo Caro" en Studia Philologica. Homenaje ofrecido a Dámaso Alonso. Madrid, Gredos, 1960, t. 1, pp. 269 - 275.

9 El inventario data de mayo de 1606, sólo dos años antes que el de Céspedes. Vid. MÉNDEZ RODRÍGUEZ, Luis. "Lecturas y miradas de un Humanista. La colección del canónigo Luciano Negrón", Archivo Hispalense, $n^{\circ}$. 252, Sevilla, 2000, pp. $115-138$. 
Arfe o las estancias capitulares de la Iglesia Mayor de Sevilla. Fue el propio Negrón quien, como mayordomo del cabildo hispalense, encargó a Céspedes las pinturas y decoraciones de la nueva Sala Capitular de la Catedral. Concretamente, en 1592, Pablo de Céspedes realizaba trabajos de dorado y decoraciones menores en el "cabildo nuevo". Más tarde, acabó realizando ocho alegorías y otros tantos tondos al fresco con santos sevillanos sobre los muros de la sala de reuniones de los capitulares ${ }^{10}$.

Sedimento de una vida: el inventario de bienes.

Centrando ahora la atención en el inventario de bienes de Pablo de Céspedes, hay que anunciar que no se trata de un registro realizado por el poseedor, destinado al control y enumeración de sus pertenencias. Un acto jurídico que se produce tras la muerte del mismo, a fin de obtener de sus bienes el rendimiento económico necesario para poder ejecutar las mandas testamentarias. Al estar realizado por escribanos públicos, la fiabilidad y objetividad de lo asentado en cuanto a cantidad y calidad es alta. Por el contrario, el escaso nivel de conocimiento que estos funcionarios podían tener de los elementos que se contabilizan, sobre todo en el caso de los objetos raros, curiosos o artísticos, complica su identificación o estudio. Un desconocimiento que no es total gracias a la actuación de los albaceas.

Córdoba, 26 de julio de 1608. En los umbrales mismos de su muerte, Pablo de Céspedes da poder a sus compañeros capitulares y amigos, el doctor Álvaro Pizaño de Palacios y al licenciado Andrés Fernández de Bonilla, canónigo y racionero de la Catedral, respectivamente, para llevar a cabo su testamento ante la imposibilidad de hacerlo personalmente por el estado terminal de su enfermedad. También los faculta para elaborar, a su fallecimiento, un inventario de sus bienes para ejecución de las mandas del testamento. Los días siguientes fueron testigos de la actuación de estos albaceas. Concretamente, el 27 y 28 de julio, así como el 24 de agosto de 1608, en presencia de Alonso Rodríguez de la Cruz, escribano público de Córdoba, los citados, acompañados por otros dos capitulares, Bernardo de Aldrete, canónigo, y Damián de Vargas, racionero, comenzaron la labor de inventario en la que fue casa del racionero Céspedes. Junto a ellos, según se recoge en el documento, estaban presentes otras muchas personas entre las que identifica a Andrés Ruiz y Juan de Peñalosa ${ }^{11}$. De ellos dos se dice que residían en la casa al servicio del difunto.

10 Vid. RECIO MIR, Álvaro: SACRVM SENATVM. Las estancias capitulares de la catedral de Sevilla. Sevilla, Universidad de Sevilla y FOCUS, 1999.

11 Peñalosa y Ruiz fueron discípulos de Pablo de Céspedes. Como era costumbre, habían residido o residian en la casa-taller del pintor durante su aprendizaje. No se puede concretar en qué fase de este aprendizaje se hallaba cada uno. Peñalosa, que después seguiría los pasos de su maestro compaginando otras actividades humanistas como la poesía, y una prebenda eclesiástica con el oficio de pintor, ya habría terminado su formación. Acerca de este pintor vid. LLAMAZARES RODRÍGUEZ, Fernando: "Juan de Peñalosa y Sandoval. Enfermedad, testamento, muerte y almoneda”, Tierras de León: Revista de la Diputación Provincial, $\mathrm{n}^{\circ}$. 41, León, 1980, pp. 89 - 96 y MELERO LEAL, María: "El pintor Juan de Peñalosa y Sandoval, de Córdoba y Astorga", De Arte: Revista de Historia del Arte, n. 8, León, 2009, pp. 67 - 86, que emana de su tesis doctoral inédita sobre el pintor. 
La labor de inventario, que por el enorme número de objetos hubo de prolongarse a lo largo de tres jornadas, dio lugar a una división del documento en sendas partes dispersas entre sí. La relación de todos los objetos, dejando de lado aquellos útiles domésticos y de ajuar que no alcanzan mayor interés, o los utensilios propios de un taller de pintura, constituyen ciertamente un conjunto de piezas conservadas que pudieron ser reunidas por Céspedes con intencionalidad de colección.

La primera de las jornadas estuvo dedicada a la apertura del acta notarial y registro de los bienes en general. Al día siguiente, fue el turno de la inmensa biblioteca del racionero y, finalmente, varios días más tarde, se contabilizaron algunos otros bienes que habrían quedado atrás, cerrándose el acta correspondiente ${ }^{12}$. Este modus operandi de los albaceas y escribanos permite realizar un análisis categorizado del registro, puesto que, aunque se trata de una sola unidad documental en tanto que en conjunto es un inventario, éste se divide en tres partes que corresponden a cada una de las jornadas que duró. De tal modo, el registro de la librería, que ocupó una jornada entera, funciona como un documento aparte, posibilitando así un análisis independiente que, por su amplitud, no es posible abarcar aquí.

Probablemente, la explicación más acertada para esta forma de proceder se fundamente, por un lado, en la lógica división de la enorme cantidad de elementos presentes en la vivienda del racionero y, por otro, en la parte práctica, pues permite establecer diversos lotes para la almoneda y ejecución de los bienes. No hay que olvidar que la utilidad de este documento no es otra que saber lo que tenía Céspedes en su casa y "poner en cobro" estos bienes para cumplir las mandas de su testamento.

La información proporcionada es abundante, y en tanto que objetiva, de interés. Permite reconstruir el entorno físico y conocer qué tenía Pablo de Céspedes y, en un nivel más profundo, ahondar en sus múltiples facetas, humanísticas y artísticas, a través de esos elementos acumulados. Buena parte de los registros dan testimonio sobre su actividad como coleccionista erudito. Al mismo tiempo, otros tantos permiten reconstruir su obrador e, incluso, su proceso creativo y metodología de trabajo.

Tras las fórmulas oficiales habituales en esta clase de documentos, los albaceas comenzaron registrando el patrimonio líquido de Céspedes, esto es, el dinero que poseía en metálico en el momento de su muerte, un total de 5.366 reales de plata, lo que equivale a unos 18 kilogramos de metal ${ }^{13}$. Seguidamente, los albaceas se centraron en objetos preciosos, sobre todo de oro y plata, fácilmente liquidables. La relación que sigue es muy variopinta, aunque permite cierta clasificación en categorías. Algo que facilita el análisis y la extracción de conclusiones. Siguiendo

12 Se ofrece la transcripción del documento. Esta corresponderá a las actas notariales levantadas los días 27 de julio y 24 de agosto de 1608 , excluyendo la correspondiente al 28 de julio de ese año, donde se registra integramente la biblioteca del humanista cordobés.

13 Esta cantidad constituía un valor económico nada despreciable para la época. No obstante, es imposible ajustar el valor monetario actual de esta cantidad, ni siquiera de su equivalente en plata, puesto que la materia base sufrió devaluaciones continuas durante los siglos XVI y XVII. Por ello, se ha establecido en unos 3 gr. el peso medio de plata que contenían estas monedas. En cualquier caso, para las equivalencias es recomendable la lectura de HAMILTON, Earl J.: El tesoro americano y la revolución de los precios en España (1501 - 1650). Barcelona, Crítica, 2000. 
este criterio se ha tratado de establecer grandes grupos de elementos atendiendo a la condición material, como por ejemplo objetos de metales preciosos; importados o exóticos; piedras preciosas o esotéricas; o bien según su uso: materiales para el ejercicio de la pintura, cuadros, esculturas y piezas artísticas; también indumentarias. Finalmente, una categoría miscelánea con elementos de todo tipo que no han podido clasificarse en ninguna de las anteriores.

Casi todos los elementos de metal precioso contabilizados corresponden al menaje doméstico, si bien destaca una cadena con doscientos treinta eslabones de oro y dos sortijas con piedras preciosas: un jacinto y un granate. Es digna de mención la enorme cantidad de medallas que aparecen en el inventario. Lamentablemente, los albaceas no se detuvieron en identificarlas, aunque sí las cuantificaron: ciento sesenta medallas de bronce y once de plata, al margen de un cajón sin cuantificar lleno de medallas, que hay que suponer eran de todo tipo. Este es, quizá, el primer rasgo evidente del coleccionismo erudito de Pablo de Céspedes, puesto que el hecho de acumular medallas antiguas y / o modernas fue una práctica habitual entre humanistas hasta el punto de constituir un artículo de intercambio. Hay que tener en cuenta que, por ejemplo, en la Roma del siglo XVI, donde Céspedes permaneció casi dos décadas, existía gran predilección por las medallas de época romana. De hecho, el papado, imbuido ciertamente de un espíritu clásico, había reeditado la costumbre de acuñar monedas y medallas conmemorativas de sus hechos singulares, influido, sin duda, por personalidades de la talla de Fulvio Orsini ${ }^{14}$.

El siguiente de los capítulos que hay que mencionar es aquel en el que se incluyen numerosos objetos exóticos provenientes de lugares tan remotos como China: porcelanas y platos. También se referencian otros procedentes de Indias. Elementos ciertamente valiosos y de origen extraño que hablan del sentido de lo exquisito en Pablo de Céspedes. Que el racionero hubiera acumulado hasta siete piezas de esta naturaleza muestra también su nivel adquisitivo y reflejan el interés por los objetos que llegaban desde Nueva España y Filipinas ${ }^{15}$. Por otra parte, existen piezas venidas de otras latitudes igualmente lejanas, como un cuchillo turco, tres alfanjes, una figura de una tortuga hecha de vidrio o un cuchillo de leche ${ }^{16}$. Toda esta enumeración tan sólo es una muestra significativa del sugerente repertorio de artificialia que formaba parte de la colección de Céspedes.

Pasando a los objetos exóticos o raros, procedentes esta vez no de la

14 Orsini era el bibliotecario del gran cardenal Farnese y además el propietario de una de las colecciones numismáticas más importantes de Occidente. Céspedes conoció sin duda a ambos personajes en su periodo romano bajo la protección del nieto de Paulo III.

15 Para principios del siglo XVII, la principal vía de penetración de la manufactura de porcelana china era el puerto de Sevilla, donde llegaba la mercancía después de meses en un viaje que, desde Manila, cruzaba el Pacífico hasta Nueva España y, de allí, surcando el Atlántico, a Sevilla. Esto convertía los artículos de este material en extraordinariamente caros y raros.

16 Utensilio cuya posesión llama la atención en tanto en cuanto era un objeto propio de judíos y musulmanes, para los que este instrumento tenía uso exclusivo en alimentos purificados, ya que el que corta la carne y está en contacto con la sangre está contaminado y es impuro. Más que exótico es un elemento que podía resultar hasta peligroso en un momento en el que la febril y desquiciada persecución de la herejía, penada con la hoguera, llevaba a sospechar de cualquier uso o costumbre relacionada con lo hebreo o musulmán. 
manufactura sino de la naturaleza, destacan elementos como un cuerno de unicornio y varias clases de conchas de animales marinos. Dentro de estas naturalia, hay que resaltar uno de los más numerosos conjuntos: el formado por las piedras preciosas y semipreciosas, a muchas de las cuales se atribuían diversas propiedades, como las de "ijada" o de jade. Traídas de ultramar, y con un color que va del verde al cárdeno, su presencia en el hogar del racionero es interesante no tanto por sus propiedades curativas, especialmente de enfermedades hepáticas, o contra el mal de ojo, sino porque las culturas mesoamericanas atribuían a estas piedras el poder de mejorar la creatividad. A esta curiosa materia hay que añadir otras como las piedras "bezares", acumulaciones calculosas de mamíferos a las que también se atribuían poderes sanadores; piedras "cornerinas" o cornalinas, ágata roja -igualmente curativa- y toda una serie de elementos líticos con diversas propiedades. Lo que no necesariamente indica una tendencia esotérica por su parte, sino más bien vuelve a poner el acento sobre su gusto por lo exótico y extravagante. Finalmente, y por citar algunas otras gemas con carácter eminentemente suntuario, en el inventario aparecen numerosos fragmentos de jaspes de varios colores, ámbar, topacios, lapislázuli, ágatas o granates. Tanto la variedad como, sobre todo, la cantidad de estas piedras induce a pensar que Céspedes las poseía no sólo como parte de su gabinete de objetos raros o curiosos, sino que las empleaba para elaboración de objetos de carácter suntuario ${ }^{17}$.

Un punto esencial en el elenco de objetos que se relacionan dentro del inventario es el que hace referencia a los utensilios propios del obrador del artista. Resulta extraordinariamente curioso el hecho de que sólo aparezcan unos cuantos elementos, poco más de media docena, como si el taller no estuviera ya en funcionamiento. Algo que llama poderosamente la atención, puesto que si bien es conocido que el racionero ya no ejercitaba el arte de la pintura ${ }^{18}$, sí consta que en su casa vivía, en ese momento al menos, Andrés Ruiz ${ }^{19}$ y Juan de Peñalosa, discípulo suyo, que, tras haber finalizado su aprendizaje, permaneció junto a su maestro atendiendo las necesidades del taller. Por otro lado, es significativa la presencia de modelos anatómicos en tres dimensiones, así como elementos relacionados con la escultura, como moldes o figuras de cera que, según Pacheco, quien afirmó verlas, servían como arquetipo para las composiciones pictóricas del artista ${ }^{20}$. Poco más se puede referir como elementos propios del taller, acaso la escueta referencia a los colores que aún poseía el artífice y que indica que el oficio no debía estar del todo inactivo.

17 Un ejemplo podrían ser los mencionados cabos para sellos o cuchillos. Incluso podría referirse a la elaboración de objetos más suntuosos como camafeos.

18 Céspedes acumuló al final de sus días diversos problemas de salud que incluso le mantuvieron privado del ejercicio de la pintura. Buen ejemplo es la información que de su propia mano se contiene en el Discurso de la comparación. Cfr. Archivo de la Catedral de Granada (A.C.G), Lib., 58, fols. $263-275$.

19 Existen pocas referencias documentales a Andrés Ruiz. Puede que se tratase de un aprendiz, aunque también pudiera ser persona a su servicio, pues no ha quedado constancia de su producción. En cualquier caso, puede relacionarse con aquel mozo que cita Pacheco en su Arte de la Pintura a propósito de una anécdota relacionada con el temperamento del racionero. Pacheco refiere que Céspedes, indignado por la admiración que causaba un jarrón que había pintado en una Santa Cena, mandó a un tal Andrés que borrase el objeto de la pintura, pues en ella debían ser admiradas las figuras y cabezas en las que tanto se había esforzado el cordobés. Cfr. PACHECO, Francisco: El Arte de la Pintura. Ed. intr. y notas de Bonaventura Bassegoda i Hugas. Madrid, Cátedra, 1990, p. 521.

20 Ibídem. p. 440, y n. 11. 
Entre la amalgama de objetos que, fuera de las categorías mencionadas, componen el asiento documental destacan aquellos que aluden a la actividad humanística de su propietario, como por ejemplo, los astrolabios, que evidencian su gusto por los instrumentos científicos, en concreto astronómicos. También se refleja la presencia de un "cave" que, tanto las transcripciones anteriores como la realizada con motivo del presente trabajo, debe identificarse como un clave. Hecho este que llevó al primer transcriptor del documento a atribuir a Céspedes capacidades musicales, ampliando así su faceta artística ${ }^{21}$. De su actividad escritora dan cuenta los mazos de cañones de plumas, y la de eclesiástico se hace patente a través de toda la indumentaria, exclusivamente clerical, así como múltiples objetos devocionales. De los vinculados a esta última faceta hay que destacar un altar de madera, decorado en blanco y oro, y un ara, elemento imprescindible para la celebración de la Eucaristía y que contribuye a la tesis, no del todo confirmada, de que Céspedes debía estar ordenado sacerdote. Respecto al altar, el hecho de que no se identifique pintura o imagen en él induce a pensar que bien pudiera tratarse de un modelo, probablemente una maqueta, del que, con las mismas características -blanco y con adornos dorados-, había realizado para una obra suya: la Virgen de la Antigua de la Catedral, en su capilla homónima.

Finalmente, hay que referirse a la colección de obras de arte que poseía el racionero en su casa. En la práctica totalidad de los casos, salvo contadísimas excepciones, no es posible delimitar qué pinturas pertenecían al quehacer de Céspedes y cuáles provenían de otras manos. Con todo, las pinturas superan la treintena, cantidad nada despreciable, tanto si se trata del remanente del obrador del pintor como del resultado de su colección. De entre los temas presentes, destacan los asuntos religiosos, si bien es significativo el elevado número de payses -paisajes- que poseía, concretamente una docena de ellos. Llama también la atención que las únicas pinturas de las que se refiere autor son del "Basano"22. Además, un tercer lienzo es identificado como copia de este autor italiano. Lamentablemente, los escasos datos que ofrece este registro impiden mayores profundidades a la hora de identificar tales obras. No obstante, en el Museo de Córdoba se ha localizado una pintura que pudiera ser la última mencionada ${ }^{23}$. Del resto de telas puede suponerse que al no identificarse autor eran de mano de su propietario. Si no todas, sí algunas, ya que al menos dos de los títulos que se dan de ellas coinciden con pinturas que hoy se tienen como de Céspedes: La Asunción y El Salvador. La primera, propiedad de la Real Academia de

21 La presencia de este instrumento de tecla indujo a Ramírez de Arellano a pensar y asegurar que Céspedes no lo tendría si no fuese para tañerlo. Cfr. RAMÍREZ de ARELLANO y DÍAZ de MORALES, Rafael: "Artistas Exhumados..." op. cit. No obstante, se proponen además dos nuevas posibilidades no necesariamente excluyentes entre sí: la primera, estaría relacionada con el sentido decorativo y escenográfico del objeto, que solía estar decorado y su posesión prestigiaba a su poseedor. La segunda, que el clave fuera el soporte para las pinturas del racionero, bien por encargo ajeno, bien por una cuestión propia.

22 También conocido como Jacopo dal Ponte, $(1515$ - 1592) fue un pintor manierista de la escuela veneciana Activo durante la segunda mitad del siglo $\mathrm{XVI}$, sus pinturas, fundamentalmente de tema religioso, gozaron de alta cotización en España.

23 En el inventario del Museo de Bellas Artes de Córdoba, figura un lienzo con el tema de Moisés haciendo brotar agua de la roca, signado como CE2111P y catalogado como copia de Bassano realizada por Pedro de Orrente. 
Bellas Artes de San Fernando de Madrid, (Inv. 0385) [1]. La segunda, también conocida como Virgen con Ángeles [2], está en el Museo de Bellas Artes de Córdoba (CE2291P). Las dimensiones de la primera $(370 \times 240 \mathrm{~cm}$.) hacen pensar que quizás lo que se halló en la casa del racionero fue la segunda, mucho más pequeña $(224 \times 127.5$ $\mathrm{cm}$. $)^{24}$. En cuanto a El Salvador, puede relacionarse con un lienzo del mismo tema ubicado en el Museo de Bellas Artes de Sevilla (CE0970P), [3]. Según Pacheco, es probable que Céspedes pintara este cuadro en Roma y, a juzgar por las características formales, tomando un icono como modelo. También se sabe que el racionero lo usó para la figura de Jesús en el lienzo con el asunto de Cristo servido por los ángeles que pintó para los jesuitas de Sevilla ${ }^{25}$. Cabe añadir que, en lo referente a la copia de pinturas antiguas imitando el estilo original, no es éste un caso aislado, puesto que en 1601 Céspedes copió la

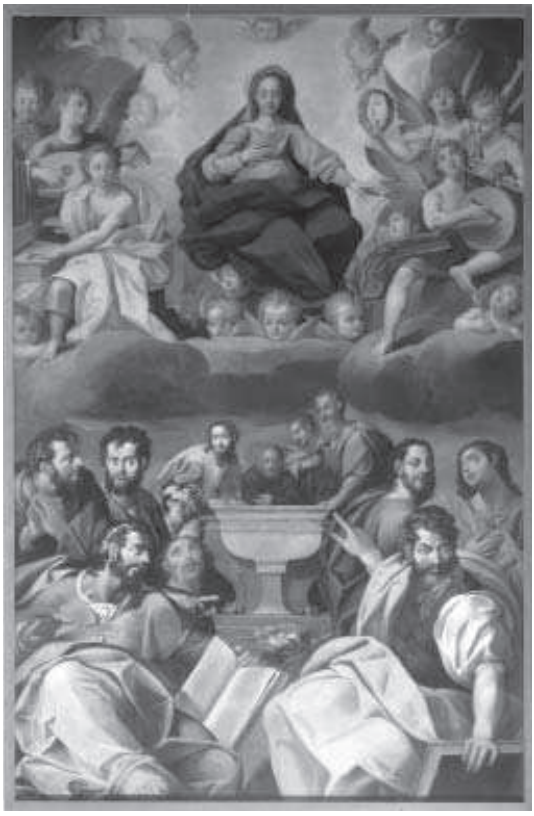

1. Pablo de Céspedes. La Asunción. Real Academia de Bellas Artes de San Fernando de Madrid.

imagen gótica de la Virgen de la Antigua de la Catedral de Sevilla en un lienzo para la capilla homónima de la Catedral cordobesa $[4]^{26}$. Estas correspondencias parecen

24 Sobre la posibilidad de que este cuadro sea efectivamente obra de Pablo de Céspedes hay un debate abierto. Garrido Hidalgo considera que se trata de la mano de un seguidor. Por el contrario, Pérez Sánchez y Navarrete la consideran obra suya y antecedente de otra pieza: la Inmaculada de Herrera el Viejo, del Palacio Arzobispal de Sevilla, también conocida como Virgen de los Huérfanos, fechándola en 1580. Vid. GARRIDO HIDALGO, Antonio: "Pablo de Céspedes. Su obra pictórica en Córdoba", en AA.VV.: Homenaje al profesor Hernández Perera. Madrid: Universidad Complutense, 1992, pp. 363 - 370, y PÉREZ SÁNCHEZ, Alfonso Emilio y NAVARRETE PRIETO, Benito: "Sobre Herrera EI Viejo", Archivo Español de Arte, El tesoro americano y la revolución. Vol. 69, n. 276, Madrid, 1996, pp. $365-388$, p. 381. Por nuestra parte, seguimos la opinión de estos dos últimos autores e identificamos la obra con la que aparece en el inventario. El cuadro figura en la colección del Museo desde 1835, fecha de la desamortización del convento o institución de carácter religiosa cordobesa que la compraría en la almoneda. Para la fecha de incorporación del cuadro a la colección, vid. http://www. juntadeandalucia.es/cultura/WEBDomus/fichaCompleta.do?ninv=CE2291P\&volver=busquedaAva nzada\&k=Céspedes, Pablo de (A). (Consultado el 1/09/2011).

25 "hizo en ella (Sevilla) algunos famossos cuadros; i entre ellos uno aventajado, para el refectorio de la Casa Professa, del convite que hizieron los Angeles a Cristo nuestro Señor, después de aver ayunado $i$ vencido al Demonio en el Desierto. Para el cual traxo un Salvador de medio cuerpo que avia estudiado en Italia, la mejor i mas bella cabeça que yo e visto pintada deste Señor". Vid. PACHECO, Francisco: Libro de descripción...op. cit., pp. 36 y 37 .

26 Nieto Cumplido publicó la atribución de esta pintura a Céspedes basándose en un documento donde se relatan las cuentas de Alonso de la Calle, patrono de la capilla, quien dice haberle dado 973 reales y 30 maravedís a cuenta de la "hechura de la ymagen y oro" más otros 210 ducados de "oro y hechura del retablo 


\begin{tabular}{|c|c|}
\hline 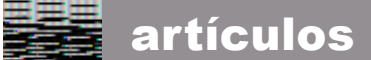 & Pedro M. Martínez Lara \\
\hline
\end{tabular}

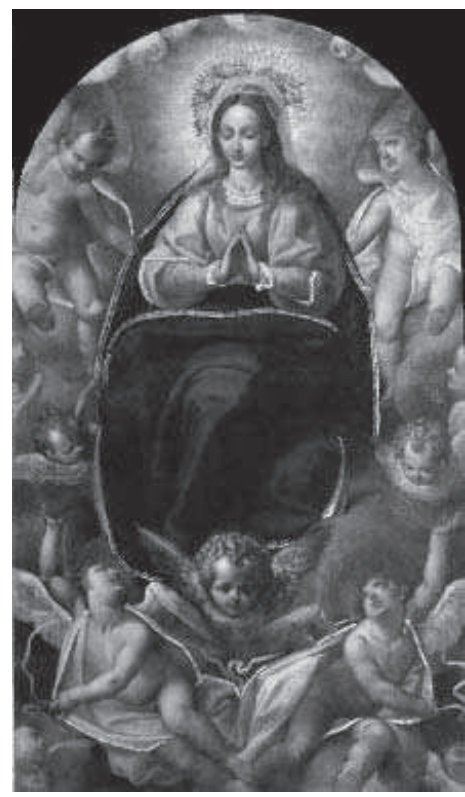

2. Pablo de Céspedes. Virgen con Ángeles. Museo de Bellas Artes de Córdoba.

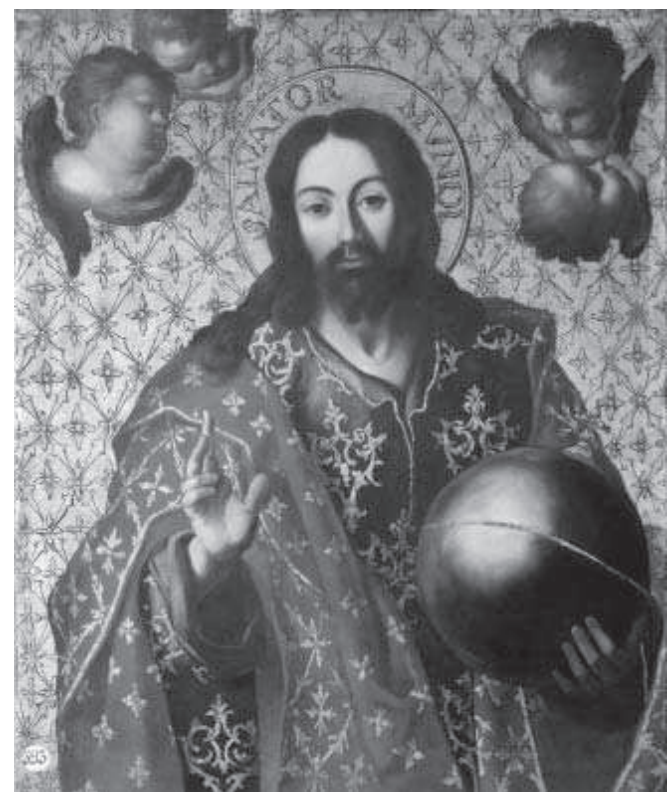

3. Pablo de Céspedes. El Salvador. Museo de Bellas Artes de Sevilla.

suficientemente fundamentadas, tanto formalmente como por lo que se ha podido rastrear de su historia material.

Entre otros objetos que podrían pertenecer al atrezzo del taller o bien a la colección del racionero, pueden contarse varias esculturas, empezando por un Cristo - ¿crucificado? - sin cruz y en funda de cuero, que podría ser el que Pacheco refiere como original de Miguel Ángel. Una figura que, respondiendo al modelo de crucificado de cuatro clavos y piernas cruzadas, habría servido como patrón a muchos artistas del momento a través de múltiples vaciados y que, traído a España por el platero Juan Bautista Franconio, fue regalado por este al racionero, quien "con mucha estimación lo traía al cuello"27. A esta curiosa imagen pueden añadírsele otras

de la capilla". Vid. NIETO CUMPLIDO, Manuel: La Catedral de Córdoba. Córdoba, Cajasur, 2007, p. 433, y A.H.P.Co., Secc. Protocolos Notariales, Leg. 10.418P, 1601, Fols. 1417 r. y 1419 v.

27 PACHECO, Francisco: El Arte..., ed. intr. y notas de Bonaventura Bassegoda i Hugas, op. cit., pp. 497, n. $6 ; 498,725$ y n. 18 de esa página. En torno a este crucificado ha existido un intenso debate. Hoy se sabe que se trata de una pieza modelada no por Miguel Ángel sino por Jacopo del Duca, partiendo, eso sí, de un dibujo del primero y que, efectivamente, vació Franconio en bronce difundiéndolo por España mediante la distribución de diversas copias. El cristo de metal -no se dice de cual- que aparece en el inventario de Céspedes parece ser el original de bronce que cita Pacheco y que es diverso del que el sanluqueño dice policromar en mate. Mi agradecimiento a José Luis Romero por sus valiosas apreciaciones sobre el contexto de esta singular pieza escultórica. Sobre el crucificado vid. GÓMEZ MORENO, Manuel: "Obras de Miguel Ángel en España”, Archivo 
esculturas enigmáticas, caso de un ídolo de bronce, el cual no es el único que poseyó el humanista, pues se conoce por su propio testimonio que perdió un objeto similar en Sevilla, aunque labrado en piedra negra por morir el criado bajo cuyo cuidado estaba la figurilla ${ }^{28}$. También hay que destacar la presencia de numerosos modelos escultóricos en cera, yeso y bronce, sin duda parte de ese laboratorio creativo que es el obrador de un artista. Finalmente, destaca la presencia de "Dos laminas de bronce con dos figuras por acabar", esto es, dos planchas de cobre para grabado cuyo proceso de apertura no habría concluido, lo que evidencia que el racionero también ejercitaba esta técnica, de la que lamentablemente no ha sido localizado ningún ejemplo.

Muchas son las conclusiones que pueden derivarse de esta visión panorámica sobre la colección de

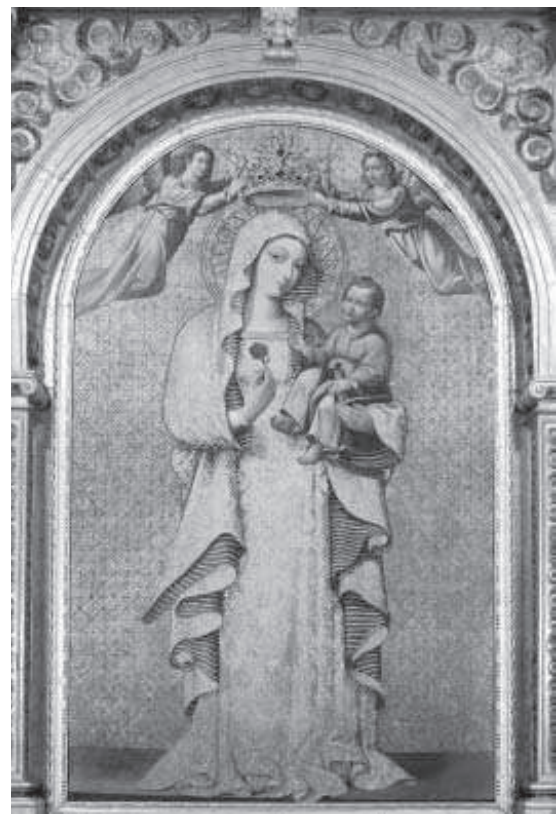

4. Pablo de Céspedes. Virgen de la Antigua. Catedral de Córdoba.

objetos curiosos y artísticos de Pablo de Céspedes. Aunque es una cuestión aceptada unánimemente que el racionero de Córdoba era mucho más que un simple pintor con carrera eclesiástica, este inventario permite verificar, a través de elementos materiales, el trasfondo claramente humanista de su propietario. Un Humanismo que se refleja no solo en sus conocidas prácticas como el amor al arte o la predilección por las letras. Este inventario supone una fuente fundamental de conocimiento acerca de Céspedes, pese a que la información que contiene sea extremadamente parca en detalles y anclada en un momento muy determinado, el de su muerte. Debido a esta circunstancia, la primera conclusión debe tornarse en reflexión: la colección que aquí se muestra es el sedimento de toda una vida, por lo que debería entenderse el momento final de su existencia como óptimo para su registro puesto que, debido a los intercambios de objetos que con frecuencia practicaban el artífice y los humanistas de

Español de Arte y Arqueología, vol. 6, n. 17, Madrid, 1930, pp. 189 - 197, pp. 192 y ss.; idem. "El Crucifijo de Miguel Ángel", Archivo Español de Arte y Arqueología, vol. 9, n. 26, Madrid, 1933, pp. 81-84; y GOLDSMITH PHILLIPS, John: "A crucifixion group after Michelangelo", Bulletin of Metropolitan Museum of Art, $n^{\circ}$. 32, New York, 1937 , pp. $210-214$.

28 El hecho lo recoge el propio Céspedes en su Discurso de la Comparación de la Antigua y Moderna Pintura y Escultura, cuyo original se conserva en el A.C.G., lib., 58, fols. 263 - 275. La cita corresponde concretamente al fol. 264v. Cfr. RUBIO LAPAZ, Jesús y MORENO CUADRO, Fernando: Escritos de Pablo de Céspedes... op. cit., p. 257 y ss. 
su entorno, la colección del racionero fue variando a lo largo del tiempo. En este sentido sirve perfectamente como ilustración el ejemplo de Pedro de Valencia, quien aparte de declarar que fue heredero de la colección de pintura de Arias Montano, pidió en una carta a Céspedes algunos lienzos de su mano, no sólo por simple predilección por la pintura sino porque quería tener obras de su amigo, quien ya era en vida admirado por su obra pictórica ${ }^{29}$. Puede abundarse en este punto en tanto que se abren nuevas perspectivas para el análisis: el intercambio de objetos entre humanistas y el prestigio de la pintura entre estos objetos.

La importante cantidad de medallas -hay que suponer que conmemorativasque se encontraron en la colección es un importante reflejo de su formación romana y filiación humanística. También el hecho en sí de las medallas conmemorativas, acuñadas bajo el axioma latino ad perpetuam rei memoriam para emular a los antiguos, remiten directamente a otra de las preocupaciones de los humanistas: el ideal de supervivencia de la memoria de lo efímero -el hombre y sus acciones- a través de la Fama.

El hecho de que Céspedes fuera pintor, a la par que coleccionista de sus propias obras, no debe distraer del auténtico sentido de su colección. Estas, aunque algunas -no todas- fuesen de su propia mano, no pueden entenderse como el remanente de su obrador, sino que a buen seguro las había mantenido consigo por motivos más elevados. Aunque la biblioteca queda aún pendiente de un estudio exhaustivo, la colección libraria de Céspedes, con más de doscientos ejemplares que abarcan varias lenguas, gran cantidad de géneros y todas las épocas, constituye mucho más que la librería de un artista: es del todo la perfecta biblioteca de un uomo virtuoso del Renacimiento.

Abundando en este último calificativo, los no pocos objetos raros, esotéricos algunos y curiosos todos, que se recogen en este inventario podrían entenderse como demérito de virtud, comparados con las medallas, libros o pinturas. Todo lo contrario. Tales elementos y utensilios, algunos de lejana procedencia como las porcelanas o los jades, denotan, por encima del afán coleccionista, la preocupación de su poseedor por el conocimiento. A la vez, son viva muestra de su sentido del gusto por lo exótico, lo extravagante, sin dejar de lado el prestigio que le proporcionaban como coleccionista. Este tipo de objetos raros, curiosos o preciosos, provocaron siempre un interés generalizado entre los humanistas coleccionistas, ávidos por combinar en sus gabinetes y en perfecta armonía, naturalia con artificialia, o lo que es lo mismo, maravillas provenientes de la naturaleza como conchas, cuernos, minerales, cristales... y otros tantos objetos artísticos, producto de la mano del hombre ${ }^{30}$.

Para rematar este análisis crítico es necesario realizar un ejercicio comparativo que permita encajar esta colección y su peso específico dentro del contexto en el que se desarrolló. Como es lógico, la colección de un pintor humanista como Céspedes no es

29 En concreto, lo que pide el humanista extremeño es un retrato de Arias Montano y alguna pintura más de su mano. Cfr. Carta de Pedro de Valencia a Pablo de Céspedes, fechada en Zafra, en agosto de 1604, cuyo original se encuentra en A.C.G., Lib., 58, fol. 330r. - 331v. Pub. en MARTíNEZ RUIZ, Juan: "Cartas inéditas de Pedro de Valencia a Pablo de Céspedes", Boletín de la Real Academia Española, nº. LIX, Madrid, 1979, pp. 371 - 397; pub. en RUBIO LAPAZ, Jesús: Pablo de Céspedes... op. cit., pp. $401-404$.

30 Este es uno de los principales argumentos del estudio de Schlosser. Vid. SCHLOSSER, Julius von: Las cámaras... op. cit. 
comparable a las grandes colecciones nobiliarias del momento, lo que, ciertamente, ya supone una contextualización. Sin embargo, es mucho más ilustrativo el establecer un análisis comparativo de la colección del cordobés con la de otro humanista procedente del estamento eclesiástico, que ha sido referido al inicio: Luciano Negrón.

La colección del sevillano destaca sobre todo por la descomunal cantidad de "cuerpos de libro" -más de 5.000- que constituían su biblioteca ${ }^{31}$. Igualmente, es digna de mención su colección artística formada por 43 lienzos y ocho esculturas ${ }^{32}$. No obstante la cantidad de libros y objetos artísticos, la colección de Negrón es notablemente más pobre en otros aspectos. Más de la mitad de los elementos de su inventario corresponden a la indumentaria y, si bien existen puntos en común con el de Céspedes -porcelanas chinas, piedras esotéricas, objetos de plata, instrumentos musicales o de astronomía-, la cantidad y variedad de artificialia y naturalia de esta colección es manifiestamente de menor entidad que la del cordobés, al menos en el aspecto humanista.

En definitiva, el análisis de este formidable documento no hace más que confirmar los valores y méritos del que, quizá, fue el pintor humanista más relevante del cambio del siglo XVI al XVII, perfecto gozne entre la elevada sensibilidad manierista y la incipiente realidad barroca que ya alboreaba.

\section{Documento $\mathrm{n}^{\circ} .1$}

1608, julio, 27 y 28, y agosto, 24, Córdoba.

Inventario de bienes de Pablo de Céspedes.

Archivo Histórico Provincial de Córdoba (A.H.P.Co.), Secc. Protocolos Notariales de Córdoba, Leg. 12.441P, 1608, s/f.

"En la ciudad de Córdoba, veynte y siete días del mes de julio de mill e seiscientos y ocho años, estando en unas casas en esta ciudad en la collación de Santa María, donde al tiempo que bibia y solía hazer su morada el señor Pablo de Céspedes, racionero que fue en la santa iglesia catedral de esta ciudad, difunto, los señores Albaro Piçaño de Palacios canónigo y licenciado Andrés Fernández de Bonilla, racioneros ambos de la dicha santa yglesia, dixeron, que como albaceas del dicho Pablo de Céspedes nombrados en el dicho poder que otorgo al dicho señor dotor para hazer y otorgar el su testamento, que paso ayer veinte y seis del presente ante mi escribano público, la comisión que por el dicho poder le dio para ymbentariar y poner cobro en sus bienes. Para la distribución dellos son benidos a las dichas

31 Hay que tener en cuenta que muchos de estos libros los poseía Negrón no tanto por coleccionismo sino por ser él quien visaba, por parte de la Inquisición, la idoneidad de los textos, por lo que recibía prácticamente todo lo que se imprimía en Sevilla.

32 Méndez apunta la posibilidad de que se traten, por la similitud en su temática y número, a las que Arias Montano donó a Pedro de Valencia. Si bien no se ha podido documentar este extremo ni los derroteros que siguieron al pasar de mano en mano hasta llegar a Negrón. Por otro lado, se da la peculiaridad de que el único autor identificado de las pinturas de Negrón es, como en el caso de Céspedes, Jacopo Bassano. Cfr. MÉNDEZ RODRÍGUEZ, Luis. "Lecturas y miradas..." op. cit., p. 120 y n. 12; GIL FERNÁNDEZ, Juan. Arias Montano en su entorno. Bienes y Herederos. Mérida, Editora Regional de Extremadura, 1998, p. 289. 
casas, para el dicho efeto de ymbentariar sus bienes y estando presente Juan Ruíz y Juan de Peñalosa que an residido en las dichas casas en servicio del dicho Pablo de Céspedes se començo el dicho ymbentario en la forma siguiente:

Los dichos señores albaceas dixeron que el dicho Pablo de Céspedes fallescio desta presente bida ayer veynte y seis del presente y acudieron luego a su escritorio, y en presencia de los dichos Andrés Ruíz y Juan de Peñalosa y de los señores dotor Bernardo de Aldrete canónigo y licenciado Damián de Bargas, racionero y de otras muchas personas y se conto el dinero que se halló en su escritorio en quatro esportillas de palma. Contado se hallo cinco mill y trescientos sesenta y seis reales en reales de plata los quales el dicho señor doctor Piçaño entregó en guarda al dicho señor dotor canónigo Aldrete.

Asimismo dixeron se halló en el dicho escritorio una cadena de oro de docientos y treynta eslabones que asimismo se entrego en guarda al diccho señor canónigo Aldrete Asimismo dixeron se halló en el dicho escritorio una xara de plata grande, $y$ otra jarra de plata, y otra más pequeña, y un plato de plata, y un pollero, y una salvilla de plata y seis trinchos de plata y un bernegal y una fuente pequeña de plata y seis cucharas de plata, y quatro tenedores de plata y una oyeruela pequeña de plata, y dos surtijas grandes de oro, la una con un Jacinto, la otra con un granate todas las quales dichas piezas con mas dos rosarios el uno de ágata y el otro de gueso entregaron en guarda al dicho señor canónigo Aldrete.

Asimismo dixeron que se halló en el dicho escritorio una porcelana de la China engastada de plata dorada, y otro plato de la china y una caxa de tres cuchillos engastada en plata, que estas pieças el dicho señor dotor Piçaño dixo tener en guarda. Ytem prosiguiendo en el dicho ymbentario, se manifiestan por mas bienes del dicho Pablo de Céspedes un rosario de doze quentas berdes

Ytem dos piedras encarnadas de yxada

Ytem dos cabo de sellos de jaspe berde

Ytem un cabo de cuchillo de lapis [Lapislázuli]

Ytem un cabo de piedra cornerina

Ytem un cabo de piedra de ágata

Ytem una piedra de ágata

Ytem una piedra cornerina y amatista

Ytem un pie de cruz de cristal en dos pieças

Ytem un pedaço grande de crsital

Otros seis pedaços de cristal chicos y grandes

Un cubilete de piedra de jaspe

Un tintero de piedra jaspe

Un cuchillo turquesco con cabo de dos piedras con baina de plata y guarnición de seda

Un cristo de metal sin cruz en una funda de cuero

Una figura de bronce

Una notomia de bronce [Anatomía]

Una cabeza de bronce 


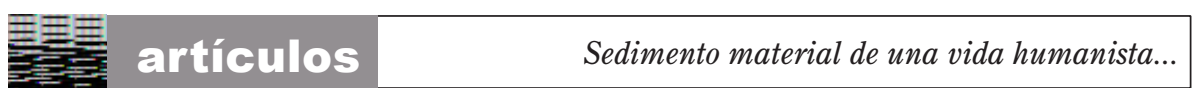

Una piedra berde

Dos caxas de antojos con dos pares de antoxos [Anteojos]

Cinco bolas de jaspe verdes negras y leonadas

Otras tres piedras de jaspe

Otra piedra de jaspe

Una cupa [copa]de bidrio con un pie de plata

Otra porcelana de la china

Dos piedras de jaspe pardo

Otra piedra de jaspe berde

Un pedaço de quinaquina para olor

Una piedra larga de ijada

Una caxa con dos cristos de cera

Un topacio que el dicho Andrés Ruíz dixo es de los erederos de Andrés Díaz, platero

Un coco con piedreçuelas

Dos caracoles en el uno estan veynte puntas de cristal

Otro caracol

Una concha grande y otra pequeña ambas con medallas en que ubo ciento $y$ sesenta medallas de bronce chicas y grandes

Dos caxas de yndias de calabaza

Una porcelana de calabaza dorada

Otras dos porcelanas pequeñas de lo mismo

Una caxeta de piedra de dobeses

Tres pedaços pequeños de cristal

Un cubilete de estaño

Dos cabos de cuchillos de leche

Otra caxuela con otras veynte puntas de cristal

Una cuenta de agata

Diez caracoles pequeños

Dos piedras de jaspe

Una tortuga de bidrio

Un libro rodete de cera

Una calabaza pequeña

Otra calabaza pequeña

Un ydolo de bronce

Un candado con llave

Nueve monedas de plata pequeñas

Una caxa de escritorio sin cajones sobre una mesa de pino

Una caxa pequeña con ocho figuras de cera

Nueve cabos de bidrio berde

Otros tres cabos del dicho bidrio

Una caxa pequeña con veyntiun granates grandes obados 
Un pedaço de bermellon

Un papel con piedra azul

Una medalla de plata

Un cuerno de unycornio

Una piedra de unicornio

Tres piedras de bruñir

Un caxon de madera con otro caxon por pie

Una escribania con tres compases tijeras cuchillos y tintero

Un relox de metal

Un cofrecillo pequeño

Once quentas de ambar amarillo

Unas quentas de Xaspe

Un relox de bidrio con caxa

Una ara

Un coco pequeño

Dos quadros del Basano [Jacopo Bassano]

Un país [Paisaje]

Un quadro de nuestra señora quando venia de xito [La Huída a Egipto]

Un quadro de nuestra señora con un niño dormido

Un quadro de Elías

Otro quadro de Moisen [Moisés]

Otro quadro de Nuestra Señora del Pópulo

Tres piedras negras de las Yndias

Un bufete de pino

Un altar de madera de blanco y oro

Una bolsa de arzon de tafilete

Una campanilla de bronce

Una ropa cachera negra

Unas mangas de umayna

Un ferreruelo de lanilla con bueltas de bayeta

Una ropa de paño

Una loba de carisea

Otro ferreruelo de paño negro

Un tornillo de fierro

Diez y siete piedras bezares chicas y grandes

Tres cajas de chocolate

Dos láminas de bronce con dos figuras por acabar

Un arca de pino

Una bancalexa de pino biexa

Otra bancalexa pequeña

Una alquitara sin sartenej[...]

Una caxa de anus dei [Agnus Dei] de nogal 
Seis cabezas de emperadores de yeso

Seis belas de cera chicas y grandes

Una piedra grande negra

Un relox de nacar quebrado

Un estante de madera

Una escobilla de limpiar ropa

Una colcha de bofetan

Dos colchones de lienzo con lana

Dos sabanas

Dos almoadas y un azirico

Dos bancos y tres tablas

Un sonbrero

Un candadillo pequeño

Un astrolabio de metal

Otros dos instrumentos de astrolabio

Una colcha de cotonía

Ochos sillas biexas

Dos candiotas pequeñas launa con bino

Quatro candeleros de estaño

Un pays con su guarnición [Paisaje]

Otros siete payses sin guarnición [Paisajes]

Una ymaxen de Nuestra Señora con guarnición

Una imajen de Nuestra Señora con un niño desnudo y el mundo en la mano

Un retrato de un onbre [Hombre]

Un quadro de la oracion del guerto en tela de plata

Dos países pequeños guarnecidos [Paisajes]

Otros dos países mas grandes [Paisajes]

Una mesa de castaño con pie y cadena

Tres alfanxes

Dos quadros de san Geronimo y Christo Nuestro Señor

Una loba i un manteo de tela de Flandes

Un arca pequeña con colores

Tres compases

Un barril de colas

Un candil de azofar

Otro candil distanio [de estaño]

Dos platos grandes de la China

Un tamiz de cedaços

Dos capas de coro una de estameña de fileyle y otra de burato

Tres sobrepellizes de lienço

Otra sobrepelliz de algodon

Dos pares de mangas de fileyle 
Tres maços de cañones para escribir Un cinto turquesco

Cinco servietas en pieza [Servilletas]

Quatro servietas cortadas [Servilletas]

Una media sutanilla [Sotanilla]

Otra servieta [Servilleta]

Dos amitos

Cinco cuellos de clérigo

Un cave

Treynta y siete belas de cera pequeñas

Dos bedrieras de bidrio en bastidores [Vidrieras]

Un caxon de madera con pie

Una copia de albaçano [Jacopo Bassano]

Un mapa grande en bastidor

Un Salbador en lienço [Salvador]

Una bancalexa larga de nogal

Nuebe macetones con limas y naranjos y otras yerbas

Un quadro de la Asuncion de Nuestra Señora en lienço

Una imaxen de Nuestra Señora al natural en lienço

Un cofre de camino

Una manga de paño de color

Unas mangas y polaynas de paño

Una sotanilla biexa

Un bufete grande biexo

Un caxon con medallas

Un envuelto con bidrios azules

Un caxon con caxas de borne

Un san Sebastián en lienço

Seis bastidores de madera sin lienço

Un candado biexo y un cerrojo

Un lienço en redondo con bastidor

Una esportilla con moldes

Otra esportilla con hierro biexo

Otra esportilla con compas

Tres calderas una grande y dos pequeñas

Un almirez y su mano

Un jamón de tozino

Una sartén bieja

Un sacador y un rallo

Unas parrillas

Un cubo con sus armas

Tres esteras de esparto pequeñas 


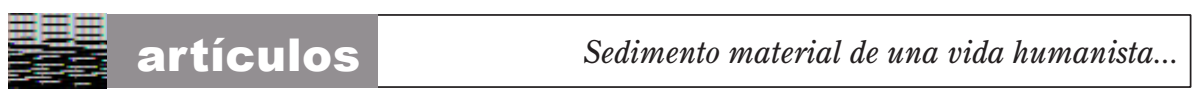

Quatro tinaxas dos grandes y dos pequeñas

Seis gallinas y cinco pollos que los dichos señores albaceas dixeron llevo el dicho Andrés de Godoi y un corcho para enfriar

En este estado los señores albaceas dixeron que dexaban y dexaron este ymbentario por ser tarde para lo proseguir y que los dichos bienes fuera de los marabedis y plata que está declarado que están en poder del señor canónigo Bernardo Aldrete y los que están en poder del dicho Andrés de Godoy los demás bienes dixeron los dexan en las dichas casas encerrados fasta que se acabe el dicho ymbentario y se pongan de manifiesto y lo firmaron los dichos señores albaceas que yo el escribano conozco siendo testigos Blas de Morales Hurtado sastre Diego de Mora texedor de lienço y Gonçalo Ruíz vezinos e moradores de Córdoba

Álvaro Piçaño de Palacios (Rub.) Licenciado Andrés de Bonilla (Rub.) Alonso Rodríguez de la Cruz

Escribano publico del número de Córdoba (Rub.) [...]

E después de lo suso dicho en la dicha ciudad de Córdoba veynte y quatro días del dicho mes de agosto del dicho año de mill y seis cientos y ocho años estando en las dichas casas en esta ciudad en la dicha collación de Santa María donde al tiempo que bibia solía hazer su morada el dicho Pablo de Céspedes que fue racionero en la santa yglesia de Córdoba los dichos señores dotor Albaro Piçaño de Palacios y licenciado Andrés Fernández de Bonylla racioneros ambos de la santa iglesia catedral desta ciudad, como albaceas del dicho Pablo de Céspedes continuando el ymbentario de bienes que quedaron del dicho difunto los manifestaron en la forma siguiente Ciento e veynte y nuebe fanegas de trigo de limpio y tres fanegas de suelos que dixeron se hallaron en las dichas casas y se llebaron por la siguridad dello a casa del señor dotor Albaro Piçaño de Palacios

Un candado biexo con llabe

Un acetre biexo

Tres bastidores de madera y seis tablas largas y un corgadixo de madera de pintor y unas faxias y un banco de pintor y unos palos biexos

Un bastidor de madera con quatro berjas de hierro

Los quales dichos bienes deste auto de ymbentario los dichos señores albaceas dixeron están de presente en las dichas casas eceto el trigo, que como dicho es, se llebo a las casas de la morada del dicho señor dotor Albaro Piçaño de Palacios por la siguridad dello y en este estado dixeron que dejaban y dexaron el dicho ymbentario por este dia para lo acabar con las solemnidades de la ley siendo testigo Juen Destrada presbitero y Juan Gómez Delgado clérigo y Gonçalo Ruíz vezinos e moradores en Córdoba y firmaronlo de sus nombres los dichos señores dotor Albaro Piçaño de Palacios y licenciado Andrés Fernández de Bonylla a los quales yo el escribano conozco

Dotor Piçaño de Palacios (Rub.) Licenciado Andrés de Bonilla (Rub.)

Alonso Rodríguez de la Cruz

Escribano publico del número de Córdoba (Rub.)". 
